\title{
LA ARCHIVÍSTICA EN LA DOCUMENTACIÓN HISTÓRICA DEL DISEÑO GRÁFICO
}

\author{
Luz del Carmen Vilchis Esquivel*
}

\begin{abstract}
Resumen
El objetivo de este trabajo es sustentar la importancia de preservar la rica diversidad de resultados de la investigación de la historia de lo diseñado como documentos de archivo vinculados con acciones como clasificar, valorar, describir y gestionar generando así las bases fundamentales para considerar a la archivística como uno de los grandes nexos interdisciplinarios del diseño. La sistematización de documentos, además de una taxonomía de medios llevada a cabo con base en los códigos, géneros y discursos de lo diseñado, incluye la clasificación en sus dos denominaciones archivísticas: el cuadro de clasificación de fondo y el cuadro de clasificación del archivo o cuadro de fondos. Metodológicamente se procede con las bases de administración de archivos digitales, cuyos procesos han sido compilados y organizados bajo estrategias para instrumentar y administrar este tipo de compilaciones que garantizan la autenticidad, fiabilidad, integridad y usabilidad de los resultados.
\end{abstract}

Palabras Clave: archivo, documentos, diseño gráfico.

\begin{abstract}
The aim of this work is to sustain the importance of preserving the rich diversity of research results in the history of the designed as archive documents linked to actions such as classify, evaluate, describe and manage thereby generating the fundamental bases for consider archiving as one of the major links of interdisciplinary design. The systematization of documents, in addition to a taxonomy of media carried out based on the codes, genres and discourses of the de-
\end{abstract}

\footnotetext{
* Escuela Nacional de Artes Plásticas, Universidad Nacional Autónoma de México; linusluca@gmail.com.
} 
signed, includes the classification in the two types of archives: the classification table of fund and the classification table of the file or table of funds. Methodologically it originates with the databases of administration of digital files, whose processes have been compiled and organized under strategies to implement and manage this type of compilations that guarantee the authenticity, reliability, integrity and usability of the results.

Keywords: Archives, Documents, Graphic Design.

\section{Introducción}

La investigación de lo diseñado genera una serie de informaciones precisas que deben ser reconocidas como documentos de archivo. Tomás Maldonado postulaba desde 1953 que "la cultura es comunicación. Todo objeto creado por el hombre debe pertenecer a las dimensiones ideológicas y materiales simultáneamente, por ende todo objeto diseñado es comunicativo. El fenómeno comunicativo es un hecho a la vez cultural y social y hoy en día la comunicación en todos los órdenes ha sido remplazada por la charla". ${ }^{1}$

La historia del diseño gráfico se refiere a un intercambio de ideas, tanto verbal como visual, que cumple su función con base en un repertorio de núcleos gráficos significativos que se reiteran en estrategias de continuidad, constancia y permanencia, se aprenden y repiten en interminables cadenas de comunicación, "es como una de esas láminas de corte transversal donde se muestran estratos y substratos de sedimentos de distintas eras [...] los diseñadores producen manifestaciones estilísticas que una vez agotadas, se arrojan figurada y literalmente $[\ldots] .^{2}$

Diseñar gráficamente es la actividad que se ocupa del comportamiento intencional de las formas, de sus combinaciones, de su coherencia asociativa, de las posibilidades funcionales y de los valores estéticos captados en el todo denominado lo diseñado. El diseño gráfico es la disciplina proyectual orientada hacia la solución de problemas de comunicación visual que el

1 Maldonado, Escritos preulmianos, pp. 91-93.

2 Heller, La anatomía del diseño, p. 1. 
hombre se plantea en su proceso de adaptación al medio según sus necesidades.

Esta disciplina se identifica con la acción humana de cambio consciente de la forma. Es creativa porque a un soporte se le agrega algo que no existía - a esta rama de estudio responde por excelencia el arte-. De esta manera el diseño gráfico se caracteriza como una forma específica de arte, aunque responde a una intención determinada que es la comunicación visual.

La tarea esencial del diseñador gráfico consiste en una transformación del entorno, expresada en objetos gráficos que por extensión modifican la condición del ser humano. Las tendencias contemporáneas para gestionar, administrar y preservar archivos digitales han evolucionado generando un campo semántico propio de la disciplina conocida como archivística o ciencia de los documentos de archivo y de las entidades responsables de sus contenidos según la cual, se reconoce que los archivos integran una parte de la memoria de la sociedad.

A pesar de que la tipología de los archivos hace énfasis en los documentos administrativos (de oficina, de concentración o intermedios), ${ }^{3}$ y de que se reconoce la existencia de los archivos históricos, los expertos establecen una distancia entre los productores y creadores de los documentos y también delimitan el ámbito de denominación de documentos de archivo, esto es importante en el ámbito del diseño en virtud de que originalmente este surge de una creación; sin embargo, cuando trasciende como documento de archivo genera producción.

Lo anterior ya plantea la primera reflexión respecto a la investigación de las colecciones de documentos diseñados. Según Antonia Heredia, ${ }^{4}$ un documento de archivo tiene un productor; es decir, el documento se produce, no tiene múltiples ejemplares sino originales múltiples, es la certificación objetiva de una acción, no genera derechos de autor y se le adjudican atributos que son importantes para su reconocimiento.

En otro contexto se sitúa lo diseñado, que es un objeto del cual existe un número considerable de reproducciones y se considera que recrea acciones que pueden existir sólo en la mente de su creador, el diseñador, quien sí

3 Heredia, "Lección 1: Archivística...", p. 19.

4 Ibid, p. 10. 
genera los derechos de autoría sobre su trabajo. Sin embargo, cada objeto diseñado tiene una historia, una serie de referencias sobre su trayectoria como medio de comunicación en una colectividad. Documentar estas acciones implica la generación de diversos expedientes que en su conjunto conforman las bases de la historia de la disciplina del diseño.

\section{La investigación de lo diseñado como documento de archivo}

La investigación de lo diseñado forma parte de la realidad documental, inicia su ciclo cuando se decide llevarla a cabo, generando así el expediente de investigación, en virtud de que tanto su forma como su contenido, además de que están fijos en un soporte determinado, generalmente de papel, devienen en unidades documentales a las cuales se les reconoce un contexto, un agente productor y relaciones de datos para su identificación, porque hay que fijar su origen, los datos del autor y del impresor, su destino primario y destinos secundarios (por ejemplo, los carteles de Imprenta Madero, realizados por Vicente Rojo, primero eran materiales de difusión para instituciones como la Universidad Nacional Autónoma de México y posteriormente se convirtieron en objetos de exhibición que han recorrido espacios como el Museo de Arte Moderno, el Museo Carrillo Gil, etc., y han generado catálogos especializados). A este expediente en el tiempo se integran otros documentos propios del proceso que, posteriormente, en una evaluación, se decidirá si se guardan para preservación a largo plazo o se eliminan.

El ciclo de estatus de los objetos, según la teoría de Abraham Moles, es una secuencia que afecta su destino final.

- Ubicación en la esfera social, en la que el género de diseño se presenta a los receptores y cumple su función de emitir un mensaje. Según el género de que se trate, tiene un lapso de existencia eficaz que varía desde los periodos extensos como la vida de un libro (que se puede conservar por años, inclusive por generaciones), hasta los más efímeros como los volantes o los programas de mano, que solo interesan en el día en que sus referentes se desarrollan.

- Ubicación en la esfera de apropiación, en la cual lo diseñado 
permanece de diversas maneras en circulación, ya sea por la calidad del diseño, porque se guarda durante un tiempo o simplemente porque permanece adherido a soportes como las paredes, los espectaculares, las cartas, etcétera.

- Ubicación en la esfera del desafecto o el rechazo, donde un juicio valoriza lo diseñado y el objeto posiblemente sea desechado o guardado en un desván.

- Ubicación en la esfera de la revaluación o segunda residencia, que comprende la conservación de lo diseñado como un objeto al que se le adjudica un excedente de sentido, un valor estético o poético relacionado con el autor, el contenido, la expresividad formal del diseño, la edad del diseño. Es común que esta etapa la experimenten ciertos objetos al envejecer. ${ }^{5}$

Lo diseñado es así prueba y testimonio de un momento de comunicación, y trasciende a otros estadios en los cuales la comunicación principal deja de tener vigencia para dar paso a la trascendencia, considerando además la mediación de quien sí se denominaría productor, que es aquella persona que no solo colecciona los objetos de diseño, también investiga los vestigios sobre su origen, creación y ubicación en cada una de las esferas que se describieron anteriormente.

Como documentos de archivo, los expedientes que se relacionan con las colecciones de lo diseñado tienen nombre, fecha, una acción a la que corresponde y manifiestan las cualidades de autenticidad, integridad, fiabilidad y disponibilidad, estando ligados invariablemente a información concreta que no puede variar, precisando

[...] la relación entre tres términos como son información, memoria y documento. La información tiene como vehículos para manifestarse: la memoria y los documentos, pero mientras la memoria olvida, el documento la fija, la acota, la hace estable. El documento de archivo que tiene voluntad de verdad otra cosa es la evidencia- es representación fija de una información concreta. ${ }^{6}$

5 Moles, Teoría de los objetos, pp. 43-45.

6 Ibid, p. 12. 


\section{Los acervos de diseño gráfico}

Uno de los problemas más importantes en la investigación de una colección de diseño gráfico tiene que ver con acciones como clasificar, valorar, describir y gestionar la calidad, además de ser insoslayable que el control de los documentos generados no sustituye el empeño por poseerlos, a pesar de la proliferación de recursos de dominio a la hora de la denominada e-gestión documental.

Los archivos requieren una sistematización previa a la existencia misma de los documentos, que incluye la clasificación en sus dos denominaciones: la primera y principal es el cuadro de clasificación de fondo en el que las unidades principales son las series que forman parte del fondo en cuestión, en el caso que nos ocupa los discursos del diseño gráfico podrían comprender dichas series; el segundo, es el cuadro de fondos en el que las unidades principales son los fondos custodiados en él y las colecciones, en el caso de haberlas, que podrían estar conformadas por los géneros de lo diseñado.

Asimismo, hay que tomar en cuenta las funciones y controles para las transferencias entendidas como la manifestación más general y regular del ingreso de los documentos, ${ }^{7}$ es decir, los denominados metadatos que tienen como antecedentes los cuadros de clasificación, elementos importantes para proporcionar certeza de cómo se pueden manejar y recuperar los diseños, modelo de ello es el archivo de la Fundación Gamboa o los acervos históricos de diseño del Palacio de Bellas Artes, que han desarrollado sistemas de metadatos para sus colecciones.

Se requiere la exposición de un sistema para asegurar que los documentos de archivo producidos a partir de la investigación histórica de lo diseñado son nombrados de forma consistente, que se identifican en ello los creadores, géneros, medios, funciones, etc., para garantizar que se tendrán en futuros archivos digitales los metadatos correctos.

Los metadatos, en tanto información de los documentos de archivo, deberían incluir como información básica acerca de cada documento de archivo: autor,

7 Heredia, Lenguaje y vocabulario archivisticos, p. 24. 
fechas (fecha de recepción, fecha de trámite, fecha de registro), receptor, asunto, nombre y número de expediente (identificador), formato, ubicación y otra información. Esto sirve para la recuperación de la información y para documentar el contexto en el cual los documentos de archivo son producidos. ${ }^{8}$

En este complejo es de suma importancia la valoración documental, puesto que en muchas instituciones se carece de esta figura y por lo regular los documentos importantes sobre la historia del diseño gráfico no son resguardados y sí es frecuente que se vean desechados. Es común ver que de manera arbitraria las administraciones destruyen este tipo de archivos porque ocupan mucho espacio; con esta forma de pensar se ha perdido mucho de la memoria gráfica de la humanidad.

La importancia de la valoración es tal que no basta con los criterios de los archiveros. Es una responsabilidad compartida entre quienes investigan, quienes archivan los documentos producidos, quienes los gestionan, custodian y sirven, y los propios usuarios de los archivos. La valoración documental tiene que estar rigurosamente regulada para una aplicación acertada. El control para ella debe residir en órganos colegiados cuyo funcionamiento debe ser dinámico a la vez que eficaz, teniendo en cuenta que en dichos órganos reside la competencia para decidir sobre la permanencia o destrucción de múltiples ejemplos de diseño gráfico.

Es un hecho que internacionalmente se estructuran sistemas que posibilitan la compilación, preservación y difusión del patrimonio cultural con base en la tecnología digital, Juan Voutssás menciona entre algunos ejemplos los proyectos

\begin{abstract}
American Memory o Digital Preservation del National Digital Information Infrastructure and Preservation Program de la Unión Americana, eContentplus y European Digital Library -también llamada Europeana. De la Comunidad Económica Europea; ARNO - Academic Research in Netherlands on line-- de Holanda, InterPARES, esfuerzo multinacional de preservación de archivos digitales coordinado por Canadá. ${ }^{9}$
\end{abstract}

8 Barnard, "Lección 6: Indicadores y buenas prácticas...", p. 10.

9 Voutssás, Preservación del patrimonio documental en México, p: xiv. 


\section{Archivos históricos sobre diseño gráfico: patrimonio cultural}

El diseño gráfico indudablemente forma parte del patrimonio cultural de un país, el nuestro es rico en modelos y Voutssás es de los autores que reconocen que los libros, revistas, periódicos, fotografías, etc., son objetos cuya historia se debe preservar, y podemos mencionar otros géneros como carteles, folletos, volantes, timbres postales, billetes, todos ellos con la misma importancia y relevancia para el conocimiento de diseñadores, estilos, escuelas que, si no son tomados en cuenta, podrían representar pérdidas significativas para la disciplina del diseño y sus registros históricos.

Es insoslayable la vinculación de los sistemas de gestión de archivos digitales con los acervos sobre la memoria del diseño gráfico; sin embargo, como bien advierten los expertos en el tema, hay que ser cuidadosos con factores como la obsolescencia tecnológica, el registro de todos los datos necesarios para recuperar la información, las condiciones de migración de los archivos de tal forma que haya permanencia y continuidad y las circunstancias que posibiliten el acceso al conocimiento histórico del diseño gráfico en esta modalidad por parte de los usuarios: estudiantes, docentes y profesionales de las diversas especialidades.

Esta perspectiva abre un nicho importante de desarrollo y oficio para los mismos investigadores del diseñado gráfico: la archivística cobra sentido porque para desarrollarla en su modalidad digital requiere de personas capacitadas en los dominios de la tecnología digital; los profesionales de la comunicación pueden y deben ser también profesionales de la información sobre el diseño gráfico.

Esto sería congruente con la carta de la UNESCO sobre la preservación de los documentos digitales, en la cual se reconoce que los recursos de información y expresión creativa se elaboran, distribuyen, utilizan y conservan cada vez más en formato electrónico y que ello da lugar a un nuevo tipo de legado: el patrimonio digital.

El patrimonio digital consiste en recursos únicos que son fruto del saber o la expresión de los seres humanos. Comprende recursos de carácter cultural, educativo, científico o administrativo e información técnica, jurídica, médica y de otras clases, que se generan directamente en formato digital o se convierten a 
éste a partir de material analógico ya existente. Los productos "de origen digital" no existen en otro formato que el electrónico. Los objetos digitales pueden ser textos, bases de datos, imágenes fijas o en movimiento, grabaciones sonoras, material gráfico, programas informáticos o páginas Web, entre otros muchos formatos posibles dentro de un vasto repertorio de diversidad creciente. A menudo son efímeros, y su conservación requiere un trabajo específico en este sentido en los procesos de producción, mantenimiento y gestión. Muchos de esos recursos revisten valor e importancia duraderos, y constituyen por ello un patrimonio digno de protección y conservación en beneficio de las generaciones actuales y futuras. Este legado en constante aumento puede existir en cualquier lengua, cualquier lugar del mundo y cualquier campo de la expresión o el saber humanos..$^{10}$

Conservar las investigaciones sobre el diseño gráfico en formatos digitales se considera un valor informativo, legal y cultural que además presenta como excedente de sentido la difusión, comunicación y formación en la visualidad a través de las redes de comunicación, permitiendo con ello su sistematización, conocimiento e investigación. Los diseñadores gráficos tienen una cualidad sensible que les permite acceder al entendimiento de este campo y tomar consciencia de las necesidades de conservación y preservación del legado del diseño gráfico en nuestro país.

\section{Investigación de lo diseñado: un nuevo paradigma de la archivística}

Los expedientes de investigación, basados en los objetos de diseño, adquieren la condición de archivo, iniciando el ciclo de vida de los documentos sobre la investigación historiográfica de las creaciones de dicha disciplina, es así como las colecciones de objetos son el preámbulo del ciclo de vida de vestigios -documentos de archivo- de las indagaciones sobre el proceso de diseño que reúnen:

10 unESCO, Carta sobre la preservación del patrimonio digital, s/datos. 
a) La información que se involucra en este complejo de producción, integrada por documentos que surgen durante la investigación y que son significativos para comprender el proceso histórico de lo diseñado.

b) El proceso de clasificación y de registro, tradicional y digital, con objeto de identificar los documentos y que estos se conserven como un archivo valorado, identificado, clasificado y divulgado que permita el acceso a investigadores del diseño.

Se sugiere que se trate de un $\mathrm{SGDAE}^{11}$ porque se precisa de la integración de los documentos del archivo de investigación sobre las colecciones de diseño, un cuadro de clasificación que sea funcional, la captura de metadatos de los documentos de archivo, el aseguramiento del uso de los documentos, un control de acceso a la información y la conservación de los documentos. La idea es que en cualquier caso, se constituya un archivo que incremente su volumen permanentemente, que sea dinámico y que continúe como un testimonio de los objetos diseñados.

Esto forma parte de lo que el investigador Alejandro Delgado Gómez denota como un paradigma archivístico. Se puede considerar, según el diplomado en administración y preservación de archivos digitales, ${ }^{12}$ que se trata de una disciplina, según Thomassen, en un período

[...] en el que el objeto es conseguir información de alta calidad, y los métodos para conseguirlo, el uso del principio de procedencia como recurso informativo de alta calidad, así como técnicas de modelado y normas descriptivas [aunque Thomassen, según afirma Delgado] no profundiza en los motivos por los que pudiera resultar necesario un cambio de paradigma. ${ }^{13}$

En el orden digital, tanto como en el orden físico pueden y deben coexistir datos cuya procedencia no surge de una única y exclusiva base de datos y cuya clasificación debe trascender la sistematización numérica y espacio-

11 Sistema de Gestión de Documentos Administrativos Electrónicos en MoReq2: Modelo de requisitos para la gestión de documentos electrónicos, p. 1.

12 Delgado, "Lección 1: normas, estándares..." en Módulo 5 en Diplomado en administración... 13 Delgado, El Centro y la Equis, p. 18. 
temporal recurriendo para su subsistencia cabal a taxonomías especializadas y propias de un campo de conocimiento peculiar como es el caso del diseño gráfico. De nuevo recurriendo a Alejandro Delgado:

¿Cuál es el orden original de un documento que no se genera secuencialmente, sino mediante la combinación no lineal de componentes [tanto análogos como] digitales no siempre evidentes para el ojo humano, y no siempre inextricablemente vinculados unos a otros.... (14 $^{14}$

Si se comprende la valoración como "una función archivística básica que consiste en determinar la conservación o eliminación de los documentos a partir de sus valores"15 y como una actividad que propone la formulación de acciones tanto para documentos físicos como digitales que permita la depuración del acervo, en este caso se sugieren los siguientes principios de valoración:

- Evaluación de la autenticidad: relativo a documentos de los que no se tienen datos, que no cuentan con el crédito de algún autor, por lo que se requeriría una investigación para demostrar y garantizar su legitimidad. En el diseño esto es trascendente; por ejemplo, se conocen series de reproducciones de los trabajos de Posada que, aunque han sido copiados de los originales, solo se les podría reconocer como facsímiles.

- La obsolescencia de los archivos: en particular esta acción se refiere a documentos electrónicos realizados con aplicaciones que ya no se encuentran en el mercado y que no es posible migrar a programas recientes. Este es un asunto muy delicado en virtud de que hasta ahora no hay un sistema operativo ni una fábrica de software que garantice la posible migración de los archivos y en diseño ha significado importantes pérdidas de creaciones llevadas a cabo con las nuevas tecnologías informáticas.

14 Ibid, p. 19.

15 Serra, "Valoración y selección de los documentos...", p. 2. 
- Duplicidad: es decir, documentos tanto físicos como digitales que por diversas circunstancias se encuentran duplicados. Hay que depurarlos, para que no se sature el archivo por la multiplicidad, y elaborar un plan de transferencia a otras entidades interesadas en ellos. Se puede mencionar el caso del Museo Nacional de Arte que tuvo que optar por la destrucción de ejemplares múltiples de carteles realizados por Madero Refosa porque ya había clasificado las piezas necesarias de un acervo y le quedaban miles de ejemplares que no podían ni almacenar ni comercializar.

- Factibilidad de preservación: condición por la cual los documentos físicos del diseño gráfico deben separarse. Es común que en el diseño haya acervos cuyos documentos suelen estar enmohecidos, requieren restauraciones y por lo mismo tampoco se pueden fotografiar o digitalizar ya que significan un riesgo para los responsables de estas acciones.

- Capacitar al equipo de trabajo para las tareas de valoración del archivo para que se asuma desde el principio del ciclo de vida, cuando "los documentos de archivo ingresen a un sistema de gestión documental."16 En este caso se sugiere que siempre se contrate como parte de equipo a un profesional, es decir, a un diseñador, para llevar a cabo la valoración de los archivos ya que es el experto en la disciplina de la cual se generarán todos los documentos del sistema.

La variedad del diseño trae consigo la diversidad de técnicas de investigación y en consecuencia la posibilidad del uso de soportes múltiples para fijar los conocimientos generados.

La unidad del fin está dada por el contenido, determinado por factores valorativos dependientes o relacionados con los factores ontológicos, epistemológicos, y lógicos de la historiografía, modelo bajo el cual se llevó a cabo la investigación.

Esto quiere decir que para comprender el diseño gráfico se implica el conocimiento de las propiedades de los códigos morfológico, cromático, tipográfico y fotográfico, así como las leyes o reglas de combinación o

16 Barnard, "Los procedimientos dentro de los sistemas de gestión...", p. 9. 
integración de estos — sintaxis, orden interno— según la concepción plástica —ni arbitraria ni subjetiva, determinada por los factores indicados- que el diseñador quiera plasmar en cada obra en particular.

El resultado de la investigación del diseño es, como otras disciplinas, una unidad de saber, un conjunto de conocimientos unificados merced a ciertos principios, pero no es un cuerpo de verdades cerradas, al contrario, se halla en relación permanente y dinámica con otros ámbitos cognoscitivos, influye en algunos y es influido por otros. En ocasiones la relación se puede definir como estrecha con una penetración tal que llegan a producirse nuevas unidades de conocimiento.

Como menciona Alicia Barnard ${ }^{17}$ hay información que cumple con las funciones de documentos de archivo. En el tema que nos ocupa, los documentos reúnen las características para ser considerados parte de un archivo: serialidad, unicidad, evidencia, etc., y "se derivan de una función o procedimiento, sirven a la rendición de cuentas, la transparencia, el acceso a la información, [...]"18 son: correos electrónicos, cartas (solicitudes, aprobaciones, accesos a acervos, permisos de publicación, entre otras), memoranda, información sobre investigaciones: bases de datos iconográficas, directorios de autores y productores, directorios de empresas, organizaciones y universidades, cotizaciones, presupuestos, dummies, correcciones de textos, cronogramas y como capital principal, el acervo de objetos de diseño gráfico.

Un proyecto habrá de considerar la validez de que existan funcionalidades del mismo en otros sistemas, entendiendo que podrían ampliarse las sedes que se hacen cargo de la producción de archivos. De igual forma, el sistema debe ser capaz de manejar un archivo híbrido con documentos físicos y digitales.

\section{Organización de archivos de investigación histórica del diseño gráfico}

La clasificación de archivos en la definición de Antonia Heredia Herrera "es la agrupación de los archivos por sus características similares en un

17 Barnard, "La implementación de un sistema...", pp. 9-15.

18 Ibid, p. 9. 
sistema de archivos." ${ }^{19}$ En general los archivos de investigación del diseño gráfico son archivos privados, por las características y condiciones de su contenido documental, se trata de archivos históricos porque sus acervos constituyen la memoria de la comunicación visual en México, asimismo se describirían como archivos híbridos porque cuentan con documentos en papel y electrónicos. Lo anterior en relación con la descripción archivística del diseño gráfico que, retomando las palabras de Luciana Duranti, está vinculada

[...] a dos elementos archivísticos con su creador ${ }^{20}$ y el tipo de usuario de estos materiales. En otros términos y siempre según Duranti, la descripción está vinculada a tres actividades: conservar el significado, mantener el control y proporcionar acceso $[\ldots]$ en un concepto unificado que absorba enteramente la ordenación, como la producción de un instrumento descriptivo principal y multipropósito. ${ }^{21}$

$\mathrm{Al}$ entender el diseño gráfico expresamos nuestro pensamiento inmediato, un pensamiento surgido de la percepción del objeto de diseño que capta sus características, contrastes de forma y color, la calidad de su soporte, la eficacia del medio y sus relaciones externas. Entender es explicar, desdoblar el diseño, precisar su contenido y conocer su significado.

Se entiende el diseño cuando se reconoce su significado: lo que se dice —el contenido de los mensajes principal y secundarios- y se identifican los elementos estructurales: dimensiones, escala, proporciones, planos, composición y jerarquía. Los signos utilizados en cada diseño gráfico se complementan de manera singular y propician su interpretación. Los observadores entienden lo diseñado en un proceso que repiten y confirman relacionando las proposiciones gráficas y su sentido; es decir, vinculando el significado con la explicación de cada diseño.

Para proponer esta clasificación se ha tomado en cuenta el respeto al principio de procedencia y el respeto a sus funciones o relación con la

19 Heredia, Lenguaje y vocabulario..., pp. 64-65.

20 Hay que recordar las diferencias conceptuales que se establecen entre los creadores y los productores. Cfr. Heredia, "Lección 1: Archivística...", p. 19.

21 Duranti, International Research on Permanent..., p. 110. 
práctica. Aquí se retoma el cuadro de Josep Matas como una propuesta de aplicación de los diferentes principios, "en cualquier caso el principio de procedencia se refiere a la unicidad del fondo atendiendo a su único productor, mientras que son los otros principios los que condicionan la clasificación interna del fondo."22

Asimismo, se puede definir como una clasificación mixta; es decir, orgánico-funcional, porque si bien sigue el criterio de una taxonomía orgánica basado en las teorías de los discursos y de la alfabetidad visual, el criterio de las funciones, es decir, las acciones determinan la ordenación.

Por el número de criterios se trata de una clasificación monodimensional porque el criterio es uniforme en cada nivel. Es trascendente comprender los contenidos de la clasificación porque en el caso de los archivos:

[...] en la medida que los documentos son clasificados y descritos, éstos proporcionan mayor valor a los usuarios [...] se podría interpretar a la contextualización de los datos ya que esta última "agrupa jerárquicamente los documentos de un fondo de acuerdo con [su procedencia* y orden original", es decir, los coloca adentro de un contexto entendible y les da significado. ${ }^{23}$

El Fondo entendido por Arévalo Jordán como "cada una de las colecciones de impresos o manuscritos de un archivo que ingresan de una determinada procedencia” 24 que en este caso componen un fondo abierto porque el organismo que lo produce está vivo.

\begin{tabular}{|c|c|c|}
\hline $\begin{array}{l}\text { Diferentes niveles del } \\
\text { fondo }\end{array}$ & $\begin{array}{l}\text { El respeto al principio del } \\
\text { fondo }\end{array}$ & Su relación con la práctica \\
\hline Fondo publicitario & $\begin{array}{l}\text { Integra las relaciones } \\
\text { de la imagen diseñada } \\
\text { con el pensamiento } \\
\text { mercantil. }\end{array}$ & $\begin{array}{l}\text { Se manifiesta en todas las } \\
\text { formas de expresión de la } \\
\text { publicidad y sus fines están } \\
\text { relacionados con la promoción } \\
\text { de objetos, productos o } \\
\text { servicios entendidos como } \\
\text { mercancías. }\end{array}$ \\
\hline
\end{tabular}

22 Herrero, "La clasificación archivística", pp. 139-140.

23 Alarcón; Barnard, "Módulo 2: Las tecnologías de Información...”, p. 5.

24 Ibid, p. 142. 


\begin{tabular}{|c|c|c|}
\hline $\begin{array}{l}\text { Diferentes niveles del } \\
\text { fondo }\end{array}$ & $\begin{array}{l}\text { El respeto al principio del } \\
\text { fondo }\end{array}$ & Su relación con la práctica \\
\hline Fondo propagandístico & $\begin{array}{l}\text { Integra las relaciones de } \\
\text { la imagen diseñada con } \\
\text { el pensamiento político. }\end{array}$ & $\begin{array}{l}\text { Es conocido también como } \\
\text { imaginería política y sus fines } \\
\text { se enfocan a la persuasión } \\
\text { o promoción de las ideas, } \\
\text { su forma de respuesta se } \\
\text { manifiesta en el voto o la } \\
\text { manifestación. }\end{array}$ \\
\hline $\begin{array}{l}\text { Fondo educativo o } \\
\text { cultural }\end{array}$ & $\begin{array}{l}\text { Integra las relaciones } \\
\text { posibles de la imagen } \\
\text { diseñada con finalidades } \\
\text { de comunicación } \\
\text { didáctica enfocadas a } \\
\text { la enseñanza formal } \\
\text {-escolarizada- o } \\
\text { enseñanza no formal. }\end{array}$ & $\begin{array}{l}\text { Comprende todas las } \\
\text { vertientes de aprendizaje: } \\
\text { familia, calle, medios } \\
\text { impresos, medios } \\
\text { audiovisuales, etc., la } \\
\text { respuesta de los perceptores } \\
\text { se encuentra en la } \\
\text { modificación tangible de } \\
\text { conductas. }\end{array}$ \\
\hline Fondo híbrido & $\begin{array}{l}\text { Son aquellos que } \\
\text { resultan de la unión } \\
\text { de dos discursos de } \\
\text { diferente naturaleza. }\end{array}$ & $\begin{array}{l}\text { Su función es de traslape } \\
\text { de intencionalidades, lo } \\
\text { cual se traduce en la posible } \\
\text { fragmentación tanto del } \\
\text { mensaje como de sus } \\
\text { resultados. }{ }^{25}\end{array}$ \\
\hline
\end{tabular}

La serie es la "sucesión o conjunto de documentos testimonio continuado de una actividad que son producidos por uno o más agentes como responsables de esa actividad [...] el nombre de la serie suele tomarse del tipo, en plural, de los documentos o unidades documentales que la integran". ${ }^{26}$

Tanto en la clasificación de fondos como de series se ha cuidado la cualidad de la consistencia, es decir, con la coherencia de la terminología y la procedencia de los documentos de archivo, así como el campo semántico de la disciplina del diseño gráfico.

25 Vilchis, Diseño. Universo de conocimiento, pp. 46-53.

26 Heredia, op. cit., pp. 166-167. 


\begin{tabular}{|c|c|c|}
\hline Series & $\begin{array}{l}\text { Principio de respeto } \\
\text { a la estructura }\end{array}$ & Clasificación \\
\hline $\begin{array}{l}\text { Serie } \\
\text { editorial }\end{array}$ & $\begin{array}{l}\text { Objetos impresos } \\
\text { cuyo diseño gráfico } \\
\text { depende de texto } \\
\text { continuo }\end{array}$ & $\begin{array}{l}\text { Proporcionan conocimiento profundo sobre } \\
\text { uno o varios temas, están condicionados por la } \\
\text { legibilidad, su duración varía desde el tiempo } \\
\text { breve hasta la permanencia indefinida. Se } \\
\text { clasifican en libro, revista, periódico, folleto, } \\
\text { cuadernillo, catálogo, informe anual. }\end{array}$ \\
\hline $\begin{array}{l}\text { Serie para- } \\
\text { editorial }\end{array}$ & $\begin{array}{l}\text { Objetos impresos } \\
\text { cuyo diseño gráfico } \\
\text { tiene como origen } \\
\text { un texto mínimo, } \\
\text { en ocasiones la } \\
\text { imagen tiene mayor } \\
\text { importancia que el } \\
\text { texto. }\end{array}$ & $\begin{array}{l}\text { Su duración es variable y efímera; tienen } \\
\text { gran proximidad con el receptor en él se } \\
\text { encuentran volantes, puntos de venta, } \\
\text { calendarios, calcomanías, etiquetas, empaques, } \\
\text { promocionales, etcétera. }\end{array}$ \\
\hline $\begin{array}{l}\text { Serie extra- } \\
\text { editorial }\end{array}$ & $\begin{array}{l}\text { Objetos impresos } \\
\text { cuyo diseño } \\
\text { siempre está } \\
\text { condicionado por la } \\
\text { imagen }\end{array}$ & $\begin{array}{l}\text { Efímeros, lejanos al receptor por sus } \\
\text { características, comprende cartel, periódico } \\
\text { mural, espectacular, escenografías, anuncio } \\
\text { mural. }\end{array}$ \\
\hline $\begin{array}{l}\text { Serie } \\
\text { indicativa }\end{array}$ & $\begin{array}{l}\text { Objetos impresos } \\
\text { que utilizan el } \\
\text { recurso de la } \\
\text { representación } \\
\text { simbólica. }\end{array}$ & $\begin{array}{l}\text { Su permanencia es de largo plazo, suelen } \\
\text { tener una proximidad media con el } \\
\text { receptor, en él se encuentran arquigrafía, de } \\
\text { identificación, sistemas de señalización, sistemas } \\
\text { museográficos. }\end{array}$ \\
\hline $\begin{array}{l}\text { Serie } \\
\text { decorativa }\end{array}$ & $\begin{array}{l}\text { Objetos } \\
\text { impresos que no } \\
\text { proporcionan } \\
\text { información y } \\
\text { carecen de texto. }\end{array}$ & $\begin{array}{l}\text { Utilizan el recurso del patrón repetitivo, son } \\
\text { próximos al receptor, son efímeros como } \\
\text { papeles decorativos, objetos promocionales o } \\
\text { decorativos, etcétera. }\end{array}$ \\
\hline $\begin{array}{l}\text { Serie } \\
\text { narrativa no } \\
\text { lineal }\end{array}$ & $\begin{array}{l}\text { Manifestaciones } \\
\text { gráficas con } \\
\text { dibujo y texto } \\
\text { organizados con } \\
\text { base en lenguaje } \\
\text { digital, su lectura es } \\
\text { electrónica. }\end{array}$ & $\begin{array}{l}\text { Limitada por las condiciones impuestas por la } \\
\text { navegación y la interactividad; la proximidad } \\
\text { con el receptor es equivalente a la cercanía } \\
\text { que este pueda tener frente al monitor y } \\
\text { su permanencia también depende de las } \\
\text { variaciones en la tecnología. }{ }^{27} \text { (Vilchis/a, } \\
2000: 54-58 \text { ) }\end{array}$ \\
\hline
\end{tabular}

27 Vilchis, op. cit., pp. 54-58. 
La unidad documental trata de la conformación de expedientes comprendida como la "agrupación de documentos testimonio y prueba de una o varias acciones reguladas por un procedimiento administrativo" y de registros o "instrumento administrativo en el que están inscritas cronológicamente acciones o transcritos, copiados o resumidos documentos expedidos o recibidos por la organización.” (Heredia/a, 2012: 18-19). Por ejemplo:

\begin{tabular}{lll}
\hline $\begin{array}{c}\text { Unidad documental } \\
\text { compuesta }\end{array}$ & $\begin{array}{c}\text { Principio de respeto al orden } \\
\text { originario histórico }\end{array}$ & Ordenación \\
\hline Expediente 1 & Antecedentes & Época prehispánica-s. XIX \\
Expediente 2 & Inicio del siglo XX & $1900-1920$ \\
Expediente 3 & Nacionalismo & $1921-1940$ \\
\hline Expediente 4 & Esplendor del diseño gráfico & $1941-1960$ \\
Expediente 5 & Academicismo & $1961-1980$ \\
Expediente 6 & Corolario del siglo XX & $1981-2000$ \\
Expediente 7 & Siglo XXI & $2000-2013^{28}$ \\
Registro de entrada & $2008-2012$ & Temporal \\
Registro de salida & $2008-2012$ & Temporal \\
Cedulario & $2008-2012$ & Temporal \\
Correspondencia & $2007-2012$ & Temporal \\
Permisos de & $2008-2021$ & Temporal \\
impresión & &
\end{tabular}

Respecto a los apoyos para sustentar la autenticidad de los documentos y con base en la Guía del Preservador del Proyecto InterPares ${ }^{29}$ y del modelo OAIS $^{30}$ (Delgado/c, 2013: 1-28), se considerarían los siguientes requisitos para que formen parte de los metadatos y del expediente del acervo digital, generando los eslabones pertinentes de una cadena de preservación en la comprensión de que "los documentos de archivo digitales deben ser cuidadosamente manejados a lo largo de toda su existencia para asegurar

28 Vilchis, Historia del Diseño Gráfico en México, pp. 8-9.

29 Guia del Preservador. Preservación de documentos de archivo digitales..., s/p.

30 Delgado, "Lección 4: El modelo OAIS...", pp. 1-28. 
que sean accesibles y legibles a lo largo del tiempo dejando su forma, contenido y relaciones intactas hasta el punto necesario para lograr su continua confianza como documentos de archivo." 31

Estas serían condiciones importantes antes de instrumentar un SGDAE por lo cual se acotan en esta propuesta:

- Requisitos de investigación de los objetos de diseño gráfico sujetos a investigación: adquisición del documento o ingesta y requisitos para que lo diseñado esté sujeto a investigación para la apertura del expediente correspondiente.

- Metadatos de identidad e integridad del documento de archivo: identidad del documento con información sobre el contenido y descripción de la conservación.

- Metadatos relacionados con la producción, conservación y difusión del expediente y los procesos que se llevarían a cabo cuando un diseño se registra como objeto de investigación en el SGDAE. ${ }^{32}$

- Clasificación y conservación de datos: información del contenido y la representación.

- Vigencia documental e integridad del documento.

Esta proposición no pasa por alto las recomendaciones de la norma ISO 15489 respecto a la "identificación sistemática y organización de las actividades de una organización y/o de los documentos en categorías que se representan en un sistema de clasificación de acuerdo con convenciones lógicamente estructuradas, métodos y reglas". ${ }^{33}$ Para lograr lo anterior se requiere de trabajo profesional para clasificar las actividades que deriven en un sistema de clasificación, en vocabularios controlados, indización y atribución de números y códigos; para ello es indispensable la asesoría profesional y un trabajo de investigación profundo y minucioso.

31 Guia..., op. cit., s/p.

32 No se habla de transferencias. Los datos han sido tomados de OAIS con la intención de preservación en el largo plazo. Cfr. Reference Model for an Open Archival Information System (OAIS), pp. 4-30 / 4-36.

33 Norma Internacional ISO 15489-1, p. 3. 


\section{Conclusión}

Tanto el diseño gráfico como sus marcos conceptuales más importantes - la comunicación gráfica y la comunicación visual — se han ampliado para plantear disyuntivas para el conocimiento y la generación de vestigios que permitan comprender la razón proyectual y la visión crítica del sentido por medio de la generación y sistematización de archivos físicos y digitales, cuyos dominios instrumentales, las nuevas tecnologías así como las formas actuales de la archivística contribuyen al dominio sin obsesión del mundo digital en el campo del diseño.

Administrar un proyecto de SGDAE para documentos de archivo emanados de la investigación sobre el diseño gráfico supone una estrategia, sin importar las dimensiones; no hay archivo que no amerite el análisis de su situación y la modernización de los procesos de gestión documental que involucra la comprensión de las necesidades de infraestructura y tecnología, de capacitación y las estrategias de instrumentación.

Los archivos custodian decisiones, actuaciones y memoria. Los archivos conservan un patrimonio único e irremplazable que se transmite de generación en generación. Los documentos son gestionados en los archivos desde su origen para preservar su valor y significado. Los documentos son fuentes fiables de información que garantizan la seguridad y la transparencia de las actuaciones administrativas. Juegan un papel esencial en el desarrollo de la sociedad contribuyendo a la constitución y salvaguarda de la memoria individual y colectiva. El libre acceso a los archivos enriquece nuestro conocimiento de la sociedad, promueve la democracia, protege los derechos de los ciudadanos y mejora la calidad de vida. ${ }^{34}$

Un SGDAE no es una actividad independiente de la logística de una organización, "el éxito de los proyectos para la implementación de un SGDAE alcanzará sus metas cuando el mismo pueda manejar los documentos de archivo digitales y físicos desde su producción hasta su disposición final", ${ }^{35}$

34 Declaración Universal sobre los archivos, s/p.

35 Barnard, "La implementación de un sistema...", pp. 14-16. 
cumpliendo las características que indica Alicia Barnard: que sea realista, que esté normalizado, que se haga con base en la compilación vinculada con el contexto y los interesados —asegurándose de que estos conocen de los beneficios- y que considere todos los factores de instrumentación así como la resistencia al cambio y opciones de solución a los posibles problemas. Los efectos para los documentos de archivo resultado de la investigación de las colecciones de diseño gráfico en un SGDAE dependen de sus propiedades formales. Sin embargo, un diseño trasciende, pervive y perdura en la conciencia y la memoria porque reúne, además de las cualidades estéticas suficientes para la comunicación y la inmutabilidad del mensaje, la perdurabilidad del recorrido histórico de la imagen aquello que logra que una obra genere interés aunque haya sido realizada antes de que uno naciera.

Algunos profesionales como Gonzalo Tassier ${ }^{36}$ coinciden en que esto surge de la necesidad de mejorar nuestra vida, pero solo es posible llevarlo a cabo si se encuentra el "alma” del diseño, el corazón, la pasión o música interna que permiten la fusión de la idea con la mano, de ahí que teóricos como Tomás Maldonado cuestionen severamente los análisis de mercado y las indagaciones motivacionales remitiéndose a la teoría de las necesidades.

La principal preocupación provocada por la pérdida de las huellas y la memoria del diseño gráfico son las nuevas generaciones porque, reflexiona Vicente Rojo, "pueden perder la conciencia de que detrás de toda imagen está la presencia de un hombre o una mujer, que son los que pueden concebir ideas, y junto a las ideas hay que conocer las manos y ver la capacidad de las propias manos, confiar en las manos, creer en las manos, utilizar las manos", demandaba Andrés Henestrosa.

El gestualismo es suficiente para comunicar, es entrar en la introspección de los contenidos expresivos. Para el maestro Omar Arroyo, pionero en la profesionalización del diseño gráfico en México, uno de los aspectos que debiera orientar las alternativas de la archivística para la conservación de los objetos físicos y digitales del diseño gráfico en México sería rescatar los matices que nos identifican como etnias autóctonas para recuperar nuestras

36 Gustavo Guerrero, “Gonzalo Tassier. Del diseño como una de las Bellas Artes”, p. 50. 
raíces, con las que podamos competir en la globalización que nos agobia, y que esto pueda diferenciarnos de otras culturas, buscando así posturas propias que pongan énfasis en el diseño artesanal, como lo han hecho Finlandia, Dinamarca, Noruega y Suecia, entre otros países.

\section{Fuentes de documentación}

Alarcón Rendón, María y Alicia Barnard Amozorrutia, "Módulo 2: Las tecnologías de Información y Comunicaciones (TIC) y su relación con las ciencias archivísticas. Lección 6: Bases de datos", en Diplomado en administración y preservación de archivos digitales, España, Fundación ASMOZ, 15 de octubre, 2012.

, "Lección 3: La implementación de un sistema de gestión de documentos de archivo, Módulo 3: Un plan para documentos de archivo: Implementación y Administración", en Diplomado en administración y preservación de archivos digitales, España, Fundación ASMOZ, 15 de noviembre, 2012.

, "Lección 4: Los procedimientos dentro de los sistemas de gestión de archivos, Módulo 3: Un plan para documentos de archivo: Implementación y Administración", en Diplomado en administración y preservación de archivos digitales, España, Fundación ASMOZ, 15 de noviembre, 2012.

Barnard Amozorrutia, Alicia y Alejandro Delgado Gómez, "Lección 6: Indicadores y buenas prácticas, Módulo 3: Un plan para documentos de archivo: Implementación y Administración", en Diplomado en administración y preservación de archivos digitales, España, Fundación ASMOZ, 15 de noviembre, 2012.

Declaración Universal sobre los Archivos. ICA_Declaracion_Universal_sobre_ los_Archivos_2010_Esp.pdf [Documento electrónico consultado el 15 de febrero de 2013].

Delgado Gómez, Alejandro, El Centro y la Equis. Una introducción a la descripción archivistica contemporánea, España, Universidad de Murcia, 2009. (Anales de Documentación, 11)

, "Lección 1: Normas, estándares, requisitos y criterios para gestión de documentos de archivo digitales (creación y mantenimiento). 
Módulo 5: Sistemas de creación y mantenimiento de documentos", en Diplomado en administración y preservación de archivos digitales, España: Fundación ASMOZ, 7 de enero, 2013.

, "Lección 4: El modelo OAIS (Open Archival Information System).

Módulo 6: Sistemas de preservación de documentos de archivo digitales auténticos y a largo plazo", en Diplomado en administración y preservación de archivos digitales, España: Fundación ASMOZ. 4 de febrero, 2013.

Duranti, Luciana y Randy Preston (eds.), International Research on Permanent Authentic Records in Electronic Systems (InterPARES) 2: Experiential, Interactive and Dynamic Records. Padova, Italy: Associazione Nazionale Archivistica Italiana, 2008.

Guerrero, Gustavo, "Gonzalo Tassier. Del diseño como una de las Bellas Artes", en El mundo del buen gusto. México, A Editores, a. 1, núm. 10, septiembre, 2009.

Guia del Preservador. Preservación de documentos de archivo digitales - guia para las organizaciones, México: Proyecto InterPares 2, Team Mexico (Traducción al español: Juan Voutssás, México, CUIB-UNAM) < http://iibi.unam.mx/ archivistica/ip3_guia_preservador_2012.pdf > [Consulta: 05/03/2013] Heller, Steven y Mirko Ilic., La anatomía del diseño. Influencias e inspiraciones del diseño gráfico contemporáneo, Barcelona, Editorial Blume, 2008.

Heredia Herrera, Antoni, "Lección 1: Archivística: delimitación y evolución. Conceptos fundamentales (documentos y archivos). Definiciones, atributos y usos. Módulo 1: Introducción a la archivística moderna", en Diplomado en administración y preservación de archivos digitales, España: Fundación ASMOZ. 25 de septiembre, 2012.

(2011). Lenguaje y vocabulario archivísticos. España: Junta de Andalucía. Consejería de Cultura.

Herrero Montero, Ana María y Alfonso Díaz Rodríguez, "La clasificación archivística" en Cruz Mundet, José Ramón (Dir.). Administración de documentos y archivos. Textos Fundamentales. Madrid: Coordinadora de Asociaciones de Archiveros (CAA) (Creative Commons), 2011.

Maldonado, Tomás, Escritos Preulmianos. Buenos Aires: Ediciones Infinito, 1997 (Colección Arte, Arquitectura y Diseño)

MoReq2: Modelo de requisitos para la Gestión de documentos electrónicos, México, Proyecto InterPARES, 2008. file://C:/Users/NiTus/Downloads/ 
MoReq2Es\%20_2_.pdf [Consulta 15/02/14]

Norma internacional ISO 15489-1, Ginebra, Secretaría Central de

ISO, 2001 www.informacionpublica.pgr.gob.SV.../sia/normativa... GEStexto1(CS).p... [Consulta: 28/02/14]

Moles, Abraham, Teoría de los objetos, Barcelona, Gustavo Gili, 1975.

Reference Model for an Open Archival Information System (OAIS), USA, Consultative

Committee for Space Data Systems (CCSDS), 2002

Serra Serra, Jordi, "Valoración y selección de los documentos electrónicos:

principios y aplicaciones", en Revista Tria, núm.12. Barcelona, Universidad de Catalunya, 2005.

uNESCO. Carta sobre la preservación del patrimonio digital. (s/f)

$<$ http://portal.unesco.org/ci/en/files/13367/10676067825Charter_

es.pdf/Charter_es.pdf > [Consulta: 03/03/2013]

Vilchis, Luz del Carmen. Diseño, Universo de conocimiento, $2^{\mathrm{a}}$ ed. México, unAm / Editorial Claves Latinoamericanas, 2000.

México, 2010. , Historia del Diseño Gráfico en México, México, INBA- Conaculta,

Voutssas Márquez, Juan, Preservación del patrimonio documental en México,

México, Cuib-unam, 2009 (Colección Tecnologías de la Información). 